\title{
Application of fly ash agglomerates in the sorption of arsenic
}

\author{
Izabela Polowczyk, Anna Bastrzyk, Tomasz Koźlecki, Piotr Rudnicki, Wojciech Sawiński, \\ Zygmunt Sadowski, Adam Sokołowski
}

\author{
Wrocław University of Technology, Faculty of Chemistry, ul. Wyb. Wyspiańskiego 27, 50-370 Wroctaw, Poland, \\ e-mail: izabela.polowczyk@pwr.wroc.pl
}

\begin{abstract}
The scope of this contribution was to investigate in detail an application of fly ash adsorbent for the removal of arsenite ions from a dilute solution. The experiments have been carried out using fly ash from black coal burning power plant „Siersza” and brown coal burning power plant „Turów” (Poland), which was wetted, then mixed and tumbled in the granulator with a small amount of cement to increase the mechanical strength of agglomerates. The measurements of arsenic adsorption from the aqueous solution were carried out in the flask (with shaking), as well as in the column (with circulation), in order to compare two different methods of contacting waste with adsorbent. The adsorption isotherms of arsenic were determined for granulated material, using the Freundlich model. Kinetics studies indicated that the sorption follows a pseudo-first-order (PFO) model (Lagergren) and the Elovich-type model.
\end{abstract}

Keywords: fly ash, adsorbents, arsenic.

Presented at VII Conference Wasteless Technologies and Waste Management in Chemical Industry and Agriculture, Międzyzdroje, 12 - 15 June, 2007.

\section{INTRODUCTION}

Arsenic is an unwanted hazardous waste generated during the processing of variety of ores, including those of copper, gold, nickel, lead and zinc' ${ }^{1}$. High toxicity of arsenic and its salts requires an efficient method of adsorption and binding to prevent leaching into the environment. Arsenite is known to be much more toxic than $\mathrm{As}(\mathrm{V})$, more soluble, and mobile under acidic conditions; hence, its separation is of great interest. As(III) ions are chemically known to present rather peculiar speciation in aqueous solution, as mainly they remain protonated, as arseniuos acid $\left(\mathrm{H}_{3} \mathrm{AsO}_{3}\right)$, at $\mathrm{pH}$ values lower than 9; in the alkaline region the form $\mathrm{H}_{2} \mathrm{AsO}_{3}{ }^{-}$starts to appear, and in the acidic the form $\mathrm{H}_{4} \mathrm{AsO}_{3}{ }^{+}$is found too, at lower concentration ${ }^{2}$. Many efforts have been made to remove arsenic from water and waste water using various adsorbents ${ }^{3}$.

Cement and hydrated lime and other pozzolanic materials, e.g. fly ash, have been widely and successfully applied for such purpose ${ }^{4,5}$. Our interest has been focused on fly ash, a common by-product of coal incineration. More than 150 millions tons of fly ash are produced annually worldwide from the combustion of coal in power plants. However, the rate of production is greater than the consumption $^{6,7}$. The relatively small percentage of the material finds an application as the ingredient of cement and other construction products; a small amount is used as a binder for the formation of agglomerates from mine tailings to prevent acid mine drainage from mine tailings ${ }^{8}$. It immobilized the reactive components, which remained resistant to weathering and leaching. More than a half of waste material is collected in dumps or ponds?. One possible solution of the problem is conversion of fly ash into zeolite by means of recrystallization ${ }^{10,11,12,13,14,15}$. Fly ashes are complex mixtures with unique, polycomponent, heterogeneous and variable composition, containing intimately associated and finely dispersed solid, liquid and gaseous components. The phase and mineral composition of fly ash normally includes an inorganic component (90 - 99\%), an organic component (1-9\%), and a fluid component (less than $0.5 \%)^{16}$. Fly ash consists mainly of silica and alumina particles, and is a strongly alkaline material of $\mathrm{pH} 10-13$ when added to water, hence, one can expect that metal ions can be removed from aqueous solutions by precipitation or electrostatic adsorption. Industrial wastewater can contain a substantial amount of heavy metal ions which may mutually enhance adsorption, act relatively independently or interfere with each other ${ }^{17}$. Arsenic can be chemically fixed into cementation environment of the solidified/stabilized matrices by three important immobilization mechanisms ${ }^{18}$. Several researchers have shown that As-immobilization is mainly controlled by the formation of Ca-As precipitates ${ }^{19}$. The recent study suggested that calcium arsenate $\mathrm{Ca}_{3}\left(\mathrm{AsO}_{4}\right)_{2}$ is a probable host for As in fly ash. Chuanyong and co-workers ${ }^{20}$ reported a significant reduction of arsenic mobility with cement because of the formation of the sparingly soluble calcium arsenate. They also confirmed the conversion of the adsorbed arsenic to calcium arsenate precipitate. Oxidation prior to immobilization with cement has been suggested to lower the leaching of $\mathrm{As}^{21}$. Arsenic was also successfully removed from samples of industrial wastewater using fly ash ${ }^{22,3}$.

Adsorption of arsenic on fly ash was found to conform to the Freundlich's isotherm ${ }^{17}$ and the efficiency of adsorption was comparable to the activated carbon. Some authors reported a better fit with the Freundlich's isotherm than the Langmuir one for arsenic adsorption onto the activated carbon $^{23}$ or ferric hydroxide ${ }^{2}$. AguilarCorrillo and co-workers ${ }^{5}$ applied the Langmuir isotherms for the sorption of $\mathrm{As}, \mathrm{Cd}$ and $\mathrm{Tl}$ onto fly ash.

Determination of the kinetics parameters and explanation of the mechanism in heterogeneous systems is often a complex procedure, as surface effects can be superimposed on chemical effects. Kinetic models including the pseudo-first-order model of Lagergren (PFO) and the pseudo-second-order (PSO) model of Ritchie have been tested very often for the simulation of the experimental results of the adsorption of heavy metals ${ }^{2}$. The rate con- 
stants for the adsorption of metal ions (zinc, lead, cadmium and copper) on fly ash were determined using the pseudo-first-order model of Lagergren ${ }^{17}$. The pseudo-second-order equation has been used for the description of arsenic, cadmium and tall adsorption kinetic onto fly ash, followed by the parabolic diffusion equation ${ }^{5}$.

The purpose of this study was to investigate the possibility of the utilization of coal fly ash as a low-cost and effective adsorbent for arsenic removal.

\section{MATERIALS AND METHODS}

The fly ashes of different origin were used to prepare a sorbent: the one from „Elektrownia Turów” power-plant (Poland) - brown coal (lignite) burned in the pulverized coal boiler (WB - unit No. 9) and another from burning of black coal in „Elektrownia Siersza” power-plant (Poland) - fluidal coal boiler (unit No. 1) - WK. The fly ash from brown coal (Turów) contains more clay minerals (aluminosilicates), while the one from black coal is silicarich. The chemical analysis indicated that $\mathrm{SiO}_{2}(20-$ $50 \%$ ), $\mathrm{Al}_{2} \mathrm{O}_{3}$ (about $30 \%$ ), $\mathrm{CaO}$ (up to $30 \%$ ) and $\mathrm{Fe}_{2} \mathrm{O}_{3}$ (about $5-6 \%$ ) are the main components of the $\mathrm{WB}$ and WK fly ash ${ }^{11,14,24}$. The X-ray diffraction analysis showed the presence of the following minerals: anhydrite, calcite, quartz and mullite. The contents of particular components in the fly ash samples differed from each other due to combustion conditions and the nature of fuel, i.e. WB sample contains more unburned coal and much more calcium (because of the lime method used for flue gas desulphurisation). The particle size analysis showed the mean diameter ( $\mathrm{d} 0.5$ ) of about $36.7 \mu \mathrm{m}$ and $28.3 \mu \mathrm{m}$ for WB and WK, respectively. Particle analysis was undertaken using the Mastersizer 2000 laser diffractometer (Malvern), equipped with the HydroMu dispersion unit (Malvern). The surface area was measured by the BET method for helium/nitrogen mixture using FlowSorbII (Micromeritics) and found to be 3.8 and $4.8 \mathrm{~m}^{2} / \mathrm{g}$ for $\mathrm{WB}$ and WK, respectively. After granulation with $15 \mathrm{wt} \%$ of portland cement in the presence of water, the surface area of agglomerates increased to 4.5 (WB) and 9.4 (WK) $\mathrm{m}^{2} / \mathrm{g}$. One can explain it by the pozzolanic reaction occurred during the hardening of agglomerates ${ }^{25}$.

\section{Granulation experiments}

The tumble agglomeration experiments have been conducted in the laboratory granulator. The agglomeration process was performed in the 6-liter and $185 \mathrm{~mm}$-diameter plastic container placed horizontally and driven by motor with the 60 r.p.m. speed. Water $(80-90 \mathrm{ml})$ was used as the binder liquid. In each experiment, $170 \mathrm{~g}$ of fly ash samples and $30 \mathrm{~g}$ of Portland blastfurnace cement (which contains up to $70 \%$ ground granulated blast furnace slag with the rest Portland clinker and a little gypsum) were taken. The agglomeration was provided for 1 hour. After this time, the green agglomerates were formed. Wet product was cured in a curing chamber at room temperature for 1 week under cover to achieve the hydration of cementitious components ${ }^{26,27,28}$.

\section{Arsenic adsorption isotherms determination}

The removal of arsenic by sorbents from the solution was determined as follows. Sorbent $(5 \mathrm{~g})$ was added to 20 $\mathrm{ml}$ of acidic As (III) stock solution (1 - 1000 ppm solution), and the resulting suspension was shaken at room temperature for $24 \mathrm{~h}$. After this time $0.5 \mathrm{ml}$ aliquot was taken and analysed spectrophotometrically (UV-Vis Helios Gamma (ThermoFisher) spectrophotometer) by means of the molybdenium blue method followed according to the standard procedure.

\section{Batch adsorption of arsenic}

$40 \mathrm{~g}$ of the fly ash agglomerates with $200 \mathrm{ml}$ of arsenic solution (100 ppm of As (III)) in the glass Erlenmeyer flask was kept in the laboratory shaker, and shaken with the speed of 60 c.p.m. for 3 days. During the first day, 0.5 $\mathrm{ml}$ aliquot was taken every $2 \mathrm{~h}$. After 2 days - twice a day.

\section{Continuous-flow adsorption of arsenic}

$40 \mathrm{~g}$ of adsorbent with $200 \mathrm{ml}$ of arsenic solution were placed in the glass column. The diameter of the column was $45 \mathrm{~mm}$, and the height $-250 \mathrm{~mm}$. The ceramic sinter was at the bottom of the column. The circulation of arsenic solution through the bed was performed using the peristaltic pomp with the $5 \mathrm{ml}$ per minute efficiency. The experiment was conducted for 3 days.

\section{Removal of arsenic from adsorbent}

After 1 week of adsorption experiments, the adsorbent was separated on sieve and washed twice with distilled water, then mixed with $200 \mathrm{ml}$ of distilled water. The leaching of As(III) was analysed after 1 day and 1 week. Arsenic content was below the detection limit of the method, i.e. 1 ppm.

\section{RESULTS}

Two samples of fly ash (WB and WK) have been agglomerated in a drum-granulator. Granulation of fine fly ash increases its workability compared to a highly dispersed material ${ }^{25,29}$. The Portland furnaceblast cement was used as a stabilizer to increase the mechanical strength and sorption capacity of aggregates. Fly ash from black coal required more water and longer time to agglomerate. Hycnar $^{25}$ explains it by higher hydrophobicity and lower wettability of WK compared to WB; this also explains better mechanical strength of agglomerates formed from the latter. Granulation of WK requires addition of cement or ground slag. Hycnar's observations have been confirmed in our studies - the addition of cement decreased water consumption and made the agglomeration easier. The different fly ash-cement-water proportions have been examined. Finally, the mixture of $85 \%$ fly ash and $15 \%$ of cement has been selected for adsorption of arsenic. The average size of agglomerates was 12.28 and $8.53 \mathrm{~mm}$, for WK and WB samples, respectively (Table 1). The pictures of agglomerates from WB and WK samples are presented in Figures 1 and 2. After curing in the humid environment for 1 week, the granules were further seasoned for 3 weeks and then subjected to adsorption experiments.

Table 1. The size of agglomerates

\begin{tabular}{|c|c|c|c|}
\hline Sample & $\mathrm{d} 0.1(\mathrm{~mm})$ & $\mathrm{d} 0.5 \pm \sigma^{*}(\mathrm{~mm})$ & $\mathrm{d} 0.9(\mathrm{~mm})$ \\
\hline WK & 9.32 & $12.28 \pm 2.38$ & 14.98 \\
\hline WB & 6.68 & $8.53 \pm 1.85$ & 11.04 \\
\hline
\end{tabular}

* Standard deviation 


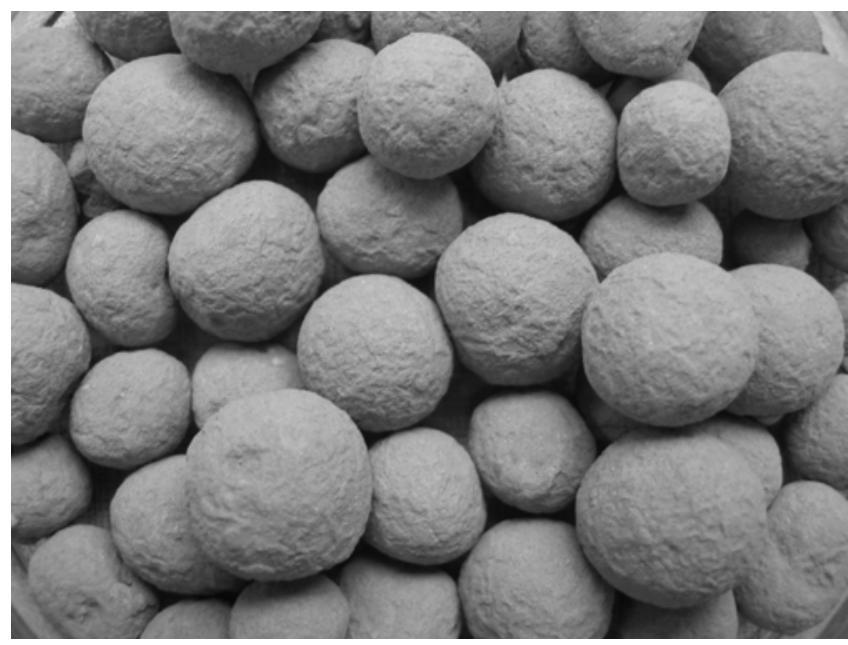

Figure 1. The picture of the agglomerates obtained from the WK fly ash

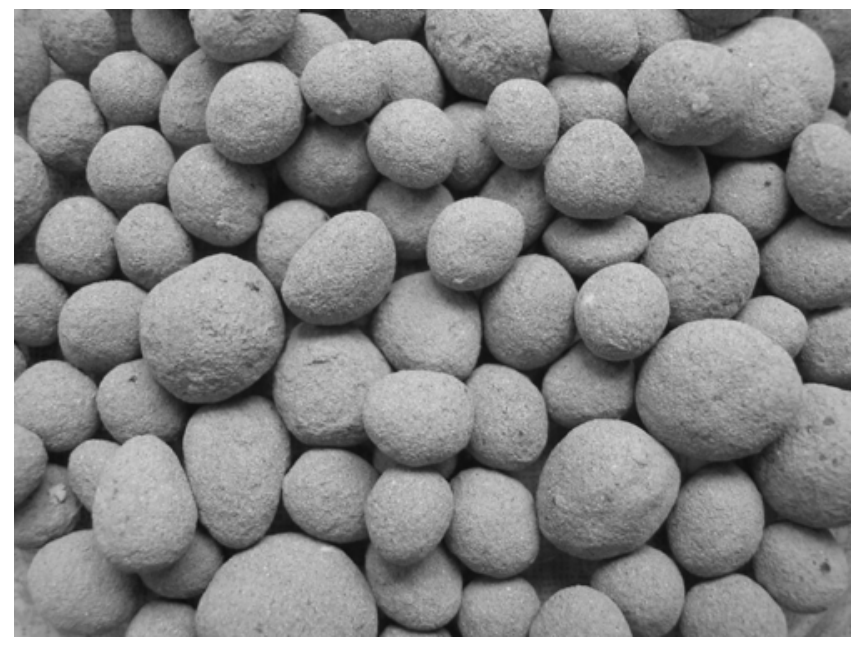

Figure 2. The picture of the agglomerates obtained from the WB fly ash

Various kinds of adsorption isotherms, especially the Langmuir and Freundlich were tested to fit the experimental data of arsenic adsorption on solid materials $\mathrm{s}^{2,5,23}$, ${ }^{30}$. In this study, the equilibrium adsorption data of As(III) for fly ash agglomerates did not obey the Langmuir equation, perhaps due to the heterogeneity of the sorbent surface $^{2,17}$. Another explanation is related to the high content of arsenic in fly ash. Konieczyński and co-workers ${ }^{31,32}$ determined the amount of As in fly ash to be as high as $1200 \mathrm{ppm}$; such high amount may strongly affect the shape of the adsorption isotherm. The best fit has been achieved using the Freundlich isotherm given by the equation: $q_{e}=K_{F} c_{e}^{1 / n}$

where $q_{e}$ is the amount of metal ions adsorbed at equilibrium $\left[\mathrm{mg} / \mathrm{g}_{\text {solid }}\right], c_{e}$ is the concentration of metal ions in solution at equilibrium [ppm], and $K_{F}[\mathrm{mg} / \mathrm{g}]$ and $n$ are constants related to adsorption capacity and adsorption intensity. Figure 3 shows the Freundlich isotherm plots for WK and WB agglomerates at native $\mathrm{pH}$ (about 11 for WK and 12 for WB). Since our research has been carried out at a low concentration of arsenic, thus, we cannot estimate the behaviour of the isotherm, i.e. the presence of the second region ${ }^{17}$. Also the solid/liquid ratio was high and there is no saturation limit as well as no Henry law limit $^{33}$. For WB both slope and intercept are higher compared to WK (Table 2 and Figure 3).
Table 2. The Freundlich constants

\begin{tabular}{|c|c|c|c|}
\hline Sample & $\mathrm{pH}$ & $1 / n(-)$ & $K_{\mathrm{F}}(\mathrm{mg} / \mathrm{g})$ \\
\hline WK & 11.0 & 0.59 & 0.13 \\
\hline WB & 12.3 & 2.16 & 0.47 \\
\hline
\end{tabular}

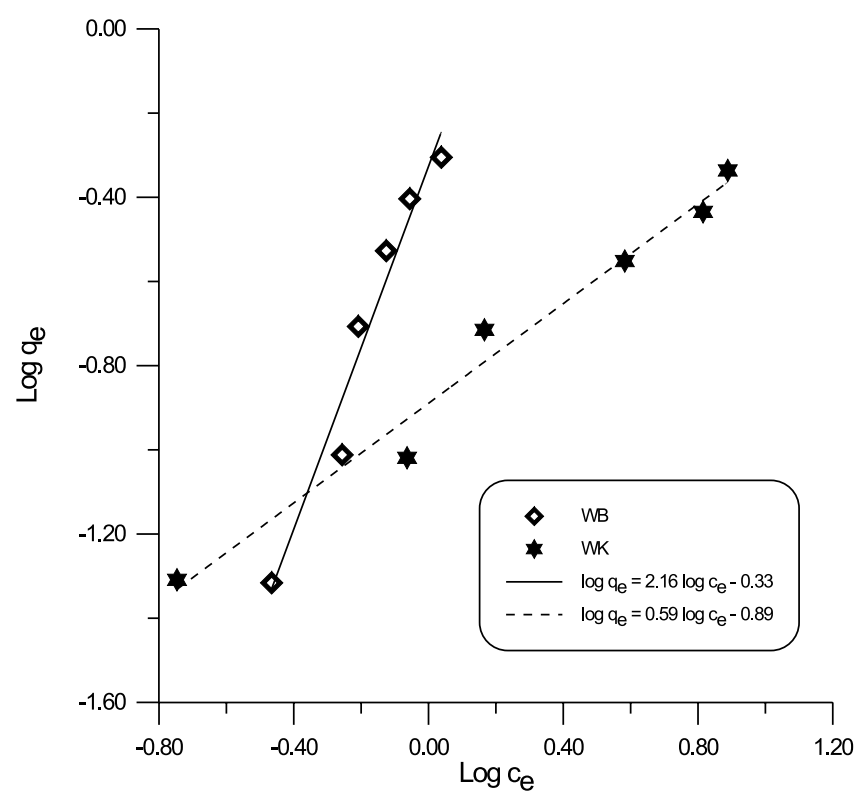

Figure 3. The Freundlich isotherm plot for the sorption of arsenic on WK and WB samples

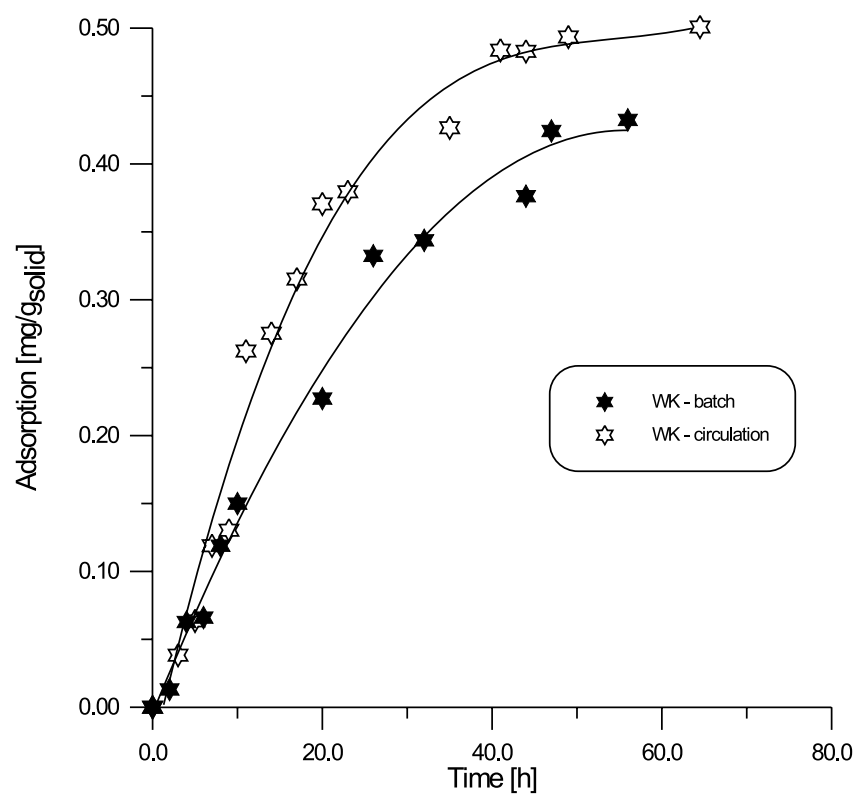

Figure 4. Sorption kinetics of arsenic onto the fly ash agglomerates (WK)

A first look into the sorption kinetic of arsenic on WK fly ash, presented in Figure 4, revealed the time necessary for its removal. Equilibrium concentration and almost a complete removal of arsenic has been achieved after 48 hours in the process conducted at circulation conditions. Probably, in batch condition more time was required to equilibrate the system.

In order to investigate the mechanisms of sorption and the potential rate controlling step, such as mass transport and chemical reaction processes, kinetic models have been used to test the experimental data. The sorption process can be described by four consecutive steps: (i) transport in the bulk of the solution, (ii) diffusion across the film surrounding the sorbent particles, (iii) particle diffusion 
in the liquid contained in the pores and in the sorbate along the pores walls, (iv) sorption and desorption within the particle and on the external surface ${ }^{30}$. In case of surface adsorption, a variation in the rate should be proportional to the first power of concentration. The most widely used for the sorption of heavy metals from a liquid solution is the Lagergren pseudo-first order equation ${ }^{4,17}$ :

$\ln \left(q_{e}-q\right)=\ln \left(q_{e}\right)-K_{a d} \cdot t$

where $q_{e}$ and $q$ are the amounts of solute adsorbed at equilibrium and at any time, $t$, respectively. The value of $K_{a d}$ (Table 3) calculated from that equation showed the better removal of arsenic in column, and WB fly ash agglomerates are slightly more effective adsorbent than WK.

Table 3. Kinetics study calculations for the Lagergren model

\begin{tabular}{|c|c|c|}
\hline Sample & $K_{\mathrm{ad}}(1 / \mathrm{min})$ & $R^{2}$ \\
\hline WK batch & 0.00068 & 0.9419 \\
\hline WK circulation & 0.00131 & 0.9782 \\
\hline WB batch & 0.00137 & 0.9796 \\
\hline WB circulation & 0.00148 & 0.9962 \\
\hline
\end{tabular}

Unfortunately, the Lagergren equation is of the same form as the equation of Boyd, which represents a film diffusion model, so differentiating between film diffusion control and the pseudo-first-order reaction control will be difficult. In the sorption studies of the intensively agitated samples, film diffusion is usually the only rate-controlling step for the first few minutes ${ }^{30}$.

A satisfactory fit with the experimental data was achieved by the application of the Elovich kinetic equation ${ }^{30,34}$ :

$q=q_{0}+\frac{1}{\beta} \cdot \ln (\alpha \cdot \beta)+\frac{1}{\beta} \ln (t)$

The parameter $\alpha$ is the initial sorption rate, the parameter $\beta$ is related to the extent of surface coverage and activation energy of chemisorption, and $q=q_{0}$ at $t=0$. The parameters calculated from the Elovich equation are given in Table 4.

Table 4. Kinetics study calculations for the Elovich-type model

\begin{tabular}{|c|c|c|c|}
\hline Sample & $\alpha(\mathrm{mg} / \mathrm{g} \cdot \mathrm{min})$ & $\beta(\mathrm{g} / \mathrm{mg})$ & $R^{2}$ \\
\hline WK batch & 0.00083 & 7.28 & 0.9559 \\
\hline WK circulation & 0.00016 & 7.58 & 0.9361 \\
\hline WB batch & 0.00158 & 7.42 & 0.9778 \\
\hline WB circulation & 0.00127 & 6.77 & 0.9668 \\
\hline
\end{tabular}

Figure 5 illustrates the comparison of the experimental data and the theoretical outcomes based on the Lagergren and Elovich models.

If the rate-limiting step is an interparticle diffusion, a plot of solute sorbed against square root of contact time should yield a straight line passing through the origin. This possibility has been tested. As it results from Figure 6, the relationship between the amount of As(III) adsorbed on fly ash and the square root of time do not give the straight line. It suggests that the pore diffusion is not the rate controlling step ${ }^{4,34}$.

\section{CONCLUSIONS}

The sorption of arsenic (As(III)) from the dilute solution has been examined onto the fly ash agglomerates under batch and column conditions. From the experimen-

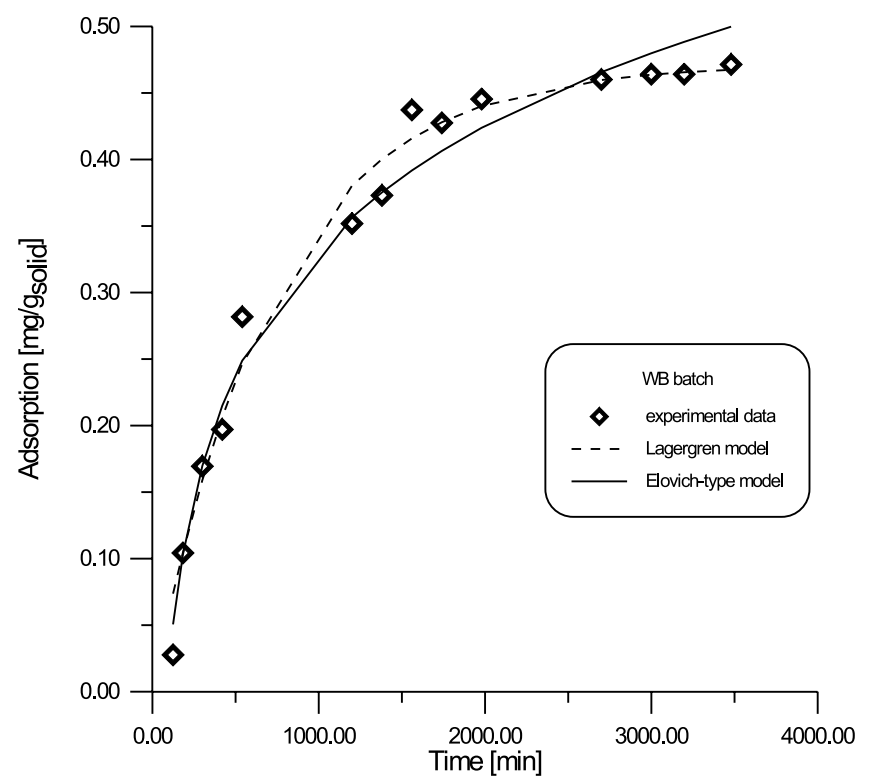

Figure 5. Sorption kinetics of arsenic onto WB. Comparison of the experimental data with the theoretical prediction

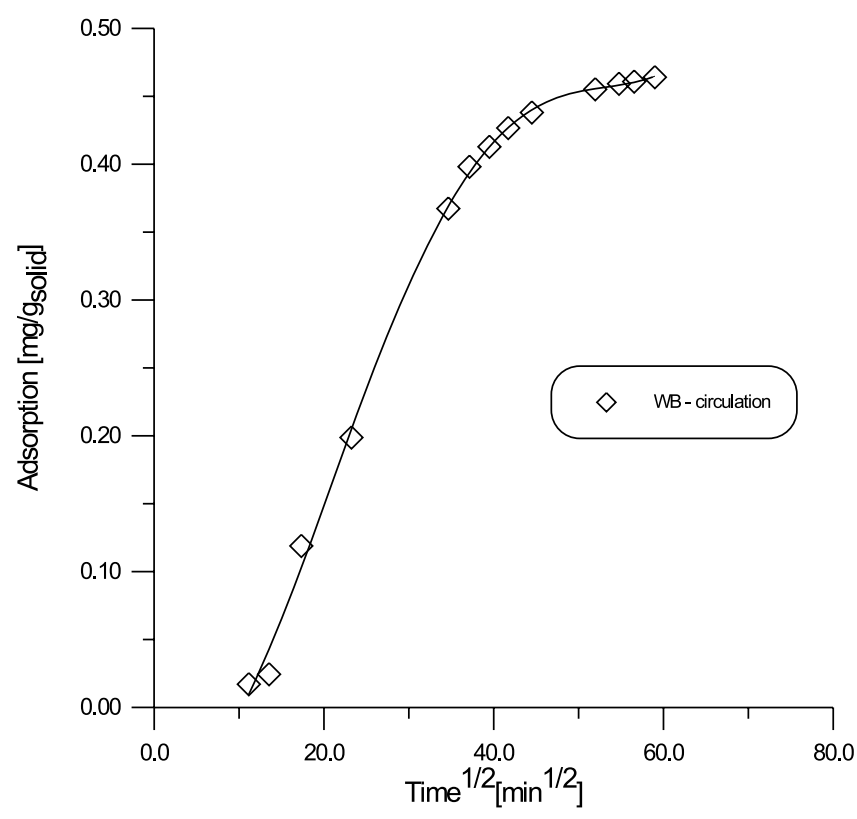

Figure 6. Plot of the amount of As(III) adsorbed vs. square root of time on WB agglomerates in circulation condition

tal results and the theoretical predictions the following conclusions can be drawn:

1. Fly-ash can be efficiently granulated into spherical agglomerates with some addition of furnaceblast cement, which increases the mechanical strength of granules and enhances the agglomeration process.

2. The granulated materials can be easily handled and stored, including packing in adsorption columns.

3. The experimental data can be fit by the Freundlich isotherm, at least at the low concentration of arsenic used in a current study. We cannot draw a conclusion about a higher concentration of As(III) ions, particularly the presence of the second region of a different slope as shown by Cho and co-workers ${ }^{17}$.

4. Our studies confirm that even the small amounts of arsenic can be removed from wastewater, lowering its concentration below $1 \mathrm{ppm}$. Unfortunately, the analytical 
method used didn't allow us to test if is it acceptable for drinking water, i.e. below $0.05 \mathrm{ppm}$.

5. The kinetic data were fitted using both the Elovich and Lagergren models. Both gave approximately the same quality of the fit, with the correlation coefficient close to 0.95. The latter one is in the same form as the Boyd film diffusion model. Unfortunately, current results are insufficient to judge whether it is the process pseudo-first order reaction controlled or diffusion controlled.

6. The WB samples are more effective sorbents than the WK ones. It can be explained by the higher porosity of the former, as shown in Figures 1 and 2.

\section{ACKNOWLEDGMENTS}

The works were partially supported by The Polish Ministry of Science and Higher Education grant No. PBZKBN-111/T09/2004.

\section{LITERATURE CITED}

(1) Leist M., Casey R. J., Caridi D.: The management of arsenic wastes: problems and prospects, J. Hazardous Mat, B67(2000)125 - 138.

(2) Deliyanni E. A, Nalbandian L., Matis K. A.: Adsorptive removal of arsenites by a nanocrystalline hybrid surfactantakaganeite sorbent, J. Colloid Interface Sci., 302(2006)458 466.

(3) Mohan D., Pittman C. U.: Arsenic removal from water/wastewater using adsorbents - A critical review, J. Hazardous Mat, 142(2007)1 - 53.

(4) Singh T. S. and Pant K. K.: Solidification/stabilization of arsenic containing solid wastes using portland cement, fly ash and polymeric materials, J. Hazardous Mat, B131(2006)29 $-36$.

(5) Aguilar-Carrillo J. Garrido F., Barrios L., GarciaGonzalez M. T.: Sorption of As, $\mathrm{Cd}$ and $\mathrm{Tl}$ as influenced by industrial by-products applied to an acidic soil: Equilibrium and kinetics experiments, Chemosphere, 65(2006)2377 - 2387.

(6) Ugurlu A.: Leaching characteristic of fly ash, Environmental Geology, vol. 46, pp. 890 - 895, 2004.

(7) Twardowska I., Szczepańska J.: Solid waste: terminological and long-term environmental risk assessment problems exemplified in a power plant fly ash study, The Science of the Total Environment, Vol. 285, pp. 29 - 51, 2002.

(8) Misra M., Yang K., Mehta R. K.: Application of fly ash in the agglomeration of reactive mine tailings, J. Hazardous Mat. 51 (1996) 181 - 192.

(9) Reijnders L.: Disposal, uses and treatments of combustion ashes: a review, Resources, Conservation and Recycling, 43(2005)313 - 336.

(10) Suchecki T. T.: Zeolites from fly ashes, [in Polish] Ossolineum, 2005.

(11) Sarbak Z., Stańczyk A., Kramer-Wachowiak M.: Characterization of surface properties of various fly ashes, Powder Technology, 145 (2004) 82 - 87.

(12) Drąg E. B: Zeolitization of fly ash (in Polish), Proccedings of XII Zeolites Forum, Ciążeń, 19 - 23 July 2005, 37 - 42 .

(13) Molina A., Poole C.: A comparative study using two methods to produce zeolites from fly ash, Minerals Engineering, vol. 17, pp. 167 - 173, 2004.

(14) Nowak W., Majchrzak-Kucęba I.: Studies of zeolites synthesized from fly ashes (in Polish), Chemia i Inżynieria Ekologiczna, T.9, Nr 5 - 6, pp. 633 - 637, 2002.

(15) Polowczyk I., Drąg E., Bastrzyk A., Sadowski Z.: Application of spherical agglomeration process in forma- tion of adsorbents from fly ash, Pol. J. Chem. Technol., 8, 4, 95 - 99, 2006.

(16) Vassilev V. V., Vassileva C. G.: Methods for characterization of composition of fly ashes from coal-fired power stations: a critical overview, Energy \& Fuels, Vol. 19, No. 3 (2005) 1084 - 1098.

(17) Cho H., Dalyoung O., Kwanho K.: A study on removal characteristics of heavy metals from aqueous solution by fly ash, J. Hazardous Mat, B127(2005)187 - 195.

(18) Phenrat T., Marhaba T. F., Rachakornkij M.: A SEM and X-ray study for investigation of solidified/stabilized arsenic-iron hydroxide sludge, J. Hazardous Mat, B118(2005)185 $-195$.

(19) Moon D. H.: et al., Arsenic immobilization by calcium-arsenic precipitates in lime treated soils, Sci. Total Environ, 330(2004)171 - 185.

(20) Chuanyong J., Korfiatis G. P., Meng X.: Immobilization mechanisms of arsenate in iron hydroxide sludge stabilized with cement, Environ. Sci. Technol., 37(2003)5050 5056.

(21) Vandecasteele C., Dutre V., Geysen D., Wauters G.: Solidification/stabilisation of arsenic bearing fly ash from the metallurgical industry. Immobilisation mechanism of arsenic, Waste Management 22(2002) 143 - 146.

(22) Iyer R. S., Scott J. A.: Power station fly ash - a review of value-added utilization of the construction industry, Resources, Conservation and Recycling, 31 (2001) 217 - 228.

(23) Lorenzen L., van Deventer J. S. J., Landi W. M.: Factors affecting the mechanism of the adsorption of arsenic species on activated carbon, Minerals Engineerings, Vol. 8, No. 4/5, pp. 557 - 569, 1995.

(24) Giergiczny Z.: The role of calcium and silicous fly ash in the formulation of modern binders and cementous materials' properties (in Polish), Cracow University of Technology, Cracow 2006.

(25) Hycnar J. J.: Factors influencing physical, chemical and functional properties of solid products from fluidized bed fuels combustion, Wydawnictwo Górnicze, Katowice 2006.

(26) Amaratunga L. M.: Cold-bond agglomeration of reactive pyrrhotite tailings for backfill using low cost binders: gypsum $\beta$-hemihydrate and cement, Minerals Engineering, Vol. 8, No. 12, pp. 1455 - 1465, 1995.

(27) Amaratunga L. M., Hmidi N.: Cold-bond agglomeration of gold mill tailings for backfill using gypsum betahemihydrate and cement as low cost binders, Canadian Metallurgical Quarterly, Vol. 36, No. 4, pp. 283 - 288, 1997.

(28) Pietsch W.: Agglomeration in industry. Occurrence and applications, Wiley, 2005, p.80.

(29) Paszek A.: Research on the utilization of the waste zinc sludge, Pol. J. Chem. Technol., 8, 3, 156 - 157, 2006.

(30) Ho Y. S., Ng J. C. Y., McKay G.: Kinetics of pollutant sorption by biosorbents: review, Separation Purification Methods, Vol. 29, No.2 (2000) 189 - 232.

(31) Staisz J., Rajchel B., Konieczyński J.: PIXE and RBS determination of trace elements in grain fractions of dust emitted from power-plant boilers, Archives of Environmental Protection, 2004, 30(1), $65-78$.

(32) Mazur J., Konieczyński J.: Distribution of trace elements in granulometric fractions of fly-ash emitted from power station (in Polish), Wydawnictwo Politechniki Śląskiej, Gliwice 2004.

(33) Do D. D.: Adsorption analysis: equilibria and kinetics, Imperial College Press, London, 1998, pp. 50 - 57.

(34) Deliyanni E. A., Peleka E. N., Matis K. A.: Removal of zinc ion from water by sorption onto iron-based nanoadsorbent, J. Hazardous Mat, 141(2007)176 - 184. 